Research Paper

\title{
The Effectiveness of Group Training of Emotional Regulation on Adolescent's Self-injury, Depression, and Anger
}

Tayebeh Vafaei $^{1}$ (D), Seyyed Abdolvahab Samavi ${ }^{2 *}$ iD, Julia L. Whisenhunt ${ }^{2}$ (D), Samaneh Najarpourian ${ }^{1}$ iD

1. Department of Educational Sciences, Faculty of Humanities, University of Hormozgan, Bandar Abbas, Iran.

2. Department of Counseling, Higher Education, and Speech-Language Pathology, Faculty of Education, University of West Georgia, Carrollton, Georgia, USA.

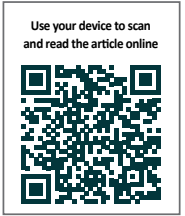

Citation Vafaei T, Samavi SA, Whisenhunt JL, Najarpourian S. The Effectiveness of Group Training of Emotional Regulation on Adolescent's Self-injury, Depression, and Anger. Journal of Research \& Health. 2021; 11(6):383-392. http://dx.doi. org/10.32598/JRH.11.6.1602.4

doi h $h$ ttp://dx.doi.org/10.32598/JRH.11.6.1602.4

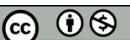

Article info:

Received: 10 Jun 2021

Accepted: 14 Sep 2021

Publish: 01 Dec 2021

\section{Keywords:}

Group training, Emotion regulation, Self-injury, Depression, Anger, Adolescents

\section{A B S T RACT}

Background: The prevalence of self-injury behavior and negative emotions in adolescents is high. This study aimed to investigate the effect of emotional regulation group training on selfinjury behavior, depression, and anger in adolescents.

Methods: The research method is quasi-experimental with a Pre-test-post-test design and a control group. The study population comprised adolescents aged 13-15 years living in Shiraz City, Iran, in 2020 with self-injury experience. A total of 30 samples were selected by multistage cluster random sampling method and randomly assigned to the two groups of experimental and control (each 15 members). A Pre-test evaluated members of both groups. Then emotion regulation group training was applied online to the experimental group. After that, the participants in both groups were assessed in the post-test. Data collection tools were deliberate self-harm inventory, Kutcher adolescent depression scale, and state and trait anger expression inventory. Descriptive Statistics (SD) and inferential statistics (multivariate covariance) were used to analyze the obtained data

Results: The results of the multivariate covariance test showed that group training of emotion regulation affected self-injury behavior, depression, and anger $(\mathrm{P}<0.05)$. Data analysis showed a significant difference between the experimental and control groups regarding self-injury, depression, and anger. Emotion-regulation group training reduced self-injury behavior and the rate of depression and anger in adolescents.

Conclusion: Emotion-regulation group training is one of the new therapies to reduce problems. This study also confirms its effectiveness on emotions and dysfunctional behaviors of adolescents.

\section{* Corresponding Author:}

Seyyed Abdolvahab Samavi, PhD.

Address: Department of Educational Sciences, Faculty of Humanities, University of Hormozgan, Bandar Abbas, Iran.

Phone: +98 (917) 7609872

E-mail:wahab.samavi@gmail.com 


\section{Introduction}

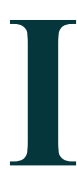

$\mathrm{n}$ recent years, nonsuicidal self-injury has been one of the new diagnostic classes of the fifth edition of the Diagnostic and Statistical Manual of Mental Disorder [1]. Self-injury behavior refers to a personal act that intentionally injures body tissues without a clear intent to commit suicide. This behavior is not fatal but very dangerous. There are currently at least 33 terms related to self-injury. This confusion and uncertainty in the definition of variables affect identifying and discovering the nature of this behavior [2].

Negative emotion is defined as a dimension of mental distress and unpleasant interaction with the environment that creates a wide range of negative moods, such as sadness and anger [3]. Depression is a set of psychological symptoms that range from mild boredom to silence and avoidance of daily activities. Depressed people interpret every event pessimistically and focus selectively on the darker dimensions of their lives. They focus on shortcomings, stressful events, and failures in their lives, attribute each event to themselves, and constantly criticize themselves [4]. Anger is an emotional state or inner feeling caused by physiological arousal, cognition, and thoughts. Frequent anger arousal can be problematic, and this arousal can activate aggressive behavior and damage psychological adjustment and personal health [5].

During adolescence, structural and functional changes in the brain are paralleled by psychosocial development [6]. In this period, adolescents try to balance, especially between emotions and cognition, understanding their existential value, improving self-awareness, choosing goals in life, being emotionally independent of family, maintaining psychological and emotional stability against environmental stressors, and establishing healthy relationships. If these characteristics of adolescence are ignored, many unhealthy behaviors are likely to occur [7].

Studies show that self-injury behavior is common among adolescents across cultures [8]. Therefore, adolescents are more prone to self-injury than other age groups. These behaviors have become more common in the last decade [9], especially among girls [10, 11]. Depression is one of the most common problems in adolescence and can cause many problems for adolescents and families. Therefore, many experts try to improve the psychological state of these people [12]. In adolescence, depression is significantly higher in the female population (ratio 2: 1) [13]. Anger is generally very intense in adolescents [14], and studies in this field have shown that if left untreated, violence in this age group will remain for a long time [15].

Emotion regulation can affect psychological problems, and emotion regulation strategies are associated with psychological distress [16] and predict subsequent adjustment [17]. Emotional regulation skills are divided into six sub-skills: emotion acceptance, emotional awareness, purposeful behavior during the emotional experience, impulse control, access to emotion regulation strategies (emotional skills), and emotional clarity [18]. Research shows that alexithymia is a multidimensional defect in recognizing and regulating emotions. Alexithymia consists of four main aspects: difficulty identifying and describing emotions, differences between emotions and physical states and emotional stimuli, limited imagination process, and external cognitive style [19].

Self-injury without suicide may be a form of opposing behavior to reduce stress and negative emotions (depression, anger, despair, etc.) or prevent negative emotions, according to the emotional regulation model. The most important motivation in this behavior is the regulation of unpleasant emotions [20-25]. A meta-analysis shows a positive and significant relationship between alexithymia, difficulty identifying emotions, difficulty defining emotions, and self-injury [26].

Depression is associated with impaired skills and negative emotions [16]. Lack of emotion regulation can lead to problematic behaviors, such as violence [27]. Studies show that people with destructive mood disorders (irritability and anger attacks) have significant problems regulating their emotions. Therefore, it is clear that emotional regulation problems in these people deserve special attention [28].

Despite the importance of self-injury behavior and emotions, limited interventions in this field have been investigated [29]. Interventions in this regard are often costly and time-consuming [30]. The group training method has benefits, such as saving time and effort, teaching social skills, and improving interpersonal relationships. These benefits have led to the widespread use of this method as the treatment of choice for individuals [31]. It can be said that the group method provides an opportunity for people to talk about their problems and express their feelings [32]. Adolescence is a period of conflict and loneliness. It is not uncommon for adolescents to feel that no one can help them. The group approach is especially suitable for adolescents, as it allows them to express conflicting feelings, discover their doubts, and recognize and share others' concerns [33]. 
Depending on the goals, group training has different approaches. One of the new approaches to self-injury behavior and negative emotions is group therapy of emotion regulation. This treatment attempts to integrate several behavioral methods based on acceptance in a comprehensive approach toward treating the emotional disorder, avoidance of experience, and self-injury behavior, presented by Gratz. Emotion regulation group therapy is based on conceptualizing emotion regulation as a multidimensional structure that includes the following areas: 1) awareness, perception, and acceptance of emotions, 2) ability to commit to purposeful behaviors and control impulsive behaviors when experiencing negative emotions, 3) using appropriate situational strategies to moderate the intensity or duration of emotions, rather than eliminating emotions, 4) the tendency to experience negative emotions as part of meaningful activities in life [18].

Much of group therapy for emotion regulation stems from two behavioral methods based on acceptance. These two approaches are acceptance and commitment therapy. Linehan's dialectical behavioral therapy emphasizes the following issues: 1) possible paradoxical effects of emotional avoidance, 2) consequences of emotion regulation resulting from acceptance emotional, and 3) the importance of controlling behaviors when emotions are present, rather than controlling the emotions themselves [34].

Interventions have shown that by focusing on emotion regulation skills, self-injury behavior can be reduced [21]. The results of emotion-regulation group therapy show that the treatment has significantly improved women's behavior with a borderline personality disorder. This type of treatment for self-injury behaviors and emotional regulation disorder is practical and valuable and reduces cognitive and emotional symptoms in individuals with borderline personality disorder $[35,36]$. The results of a case study also show that emotion-regulation therapy has a positive effect on reducing the frequency of self-injury behavior, depression, anxiety, and adolescent emotionalregulation problems [37].

Research shows that emotion-regulation training reduces depression and aggression in adolescents. This training can reduce negative emotions, make people aware of their emotions, and accept and express emotions on time $[28,38]$.

Based on the findings of other studies, emotion regulation training based on dialectical behavior therapy reduces students' anxiety and anger [39]. Emotion-regulation training promotes the person's interaction with peers, increases awareness, acceptance, and expression of emotions. It can be an effective intervention to improve students' emotions [40] and emotional adjustment [41].

Adolescents constitute a significant part of the population, and they are the main assets that play an essential role in governing the country's future. Considering the factors related to this critical period, which exposes adolescents to more and newer critical situations, is of great importance for improving their comprehensive situation. It is necessary to study and eliminate the underlying factors that cause mental and psychological problems and maintain the health of these future makers. The prevalence of critical risk factors, such as self-harming behaviors, depression, and anger among Iranian adolescents, is worrying. There is limited information and little research on emotional-regulation intervention and its effectiveness, especially in this field. Therefore, the present study seeks to perform as a mediating group among adolescents. Specialists can use the study results to teach these adolescents more adaptive and practical ways to achieve their goals.

\section{Methods}

To evaluate the effectiveness of group training, we used a quasi-experimental method with a Pre-test-post-test design and a control group. The study population comprised all 13 to 15 years old girls in Shiraz City, Iran, in 2020 who had self-injury experience. A total of 30 girls were selected based on the multi-stage cluster random sampling method. Four junior high schools were randomly selected from the education districts of Shiraz. In the next step, three classes from each school (seventh, eighth, and ninth grade) randomly complete a deliberate self-injury questionnaire. In the next stage, 30 adolescents with a history of self-injury behavior based on the questionnaire were selected as a sample and randomly assigned to two groups of experimental and control (each 15 members). Thus, the inclusion criteria were being female adolescents of 13 to 15 years old and at least one experience of self-injury without suicidal ideation during the past year. Before group training, members of both groups were assessed in the Pre-test. Emotion adjustment group training was applied to the experimental group, while the control group did not receive any training. Then, the participants in both groups were evaluated in the post-test to measure the effect of the independent variable (group training) on dependent variables (self-injury behavior, depression, and anger). It should be noted that this method is usually done in situations where it is impossible to control all relevant variables in the research, so by accurately identifying the factors that 
affect the external and internal validity, relative control is possible. To apply maximum control, the groups were selected from a homogeneous community, and the subjects were randomly assigned to the experimental and control groups. The inclusion criteria were being female, having self-injury experience, and being 13 to 15 years old. The exclusion criteria were any type of psychological disorder, simultaneous participation in other training, counseling courses, and absence of more than three sessions in training sessions.

\section{Measurement tools}

\section{Deliberate Self-harm Inventory (DSHI)}

This questionnaire was designed by Grtaz (2001) to measure various types of self-harming behavior in the non-patient community. This questionnaire contains 17 descriptive phrases on the common intentional selfinjury behaviors (scratching the head and face, scratching and piercing the skin, burning, engraving writings and photos on the skin, etc.). Each phrase asks about the duration of various self-injury behaviors in the past year. Scoring included yes (score 1) and no (score 0 ). Gratz calculates the Cronbach $\alpha$ coefficient of the questionnaire as 0.82 and its reliability coefficient after two weeks (test-retest) as 0.68 . The Cronbach $\alpha$ coefficient on the Iranian sample is 0.71 , which indicates acceptable reliability and validity. The content of the test is obtained through a survey of psychologists and educational scientists [42].

\section{Kutcher Adolescent Depression Scale (KADS-II)}

The scale was developed in 2002 by Kutcher to measure the symptoms and severity of depression in adolescents 12 to 20 years old. It is a type of short scale for measuring that can be used in a short time and without fatigue. The tool itself is a report that has 11 items, and the subject should answer each phrase according to the mood that subject has experienced in the last week with a 4-point Likert scale, from "very rare" (score 0), "sometimes" (score 1), "most of the time" (score 2), and "I always feel that way" (score 3) respond to this tool. Scoring on this scale is straightforward, and the subject score can vary from 0 to 33. The higher the score, the higher would be the depression. The scale also has 2 subtests (major depression and suicidal ideation). Research on adolescents and young people in Nigeria shows that the Cronbach $\alpha$ is $90 \%$ of the total scale, and the validity of the questionnaire concerns the two-dimensional method. Another study reported $88 \%$ reliability and $79 \%$ internal consistency [43].
Spielberger's State and Trait Anger Expression Inventory (STAXI-2)

This test consists of three parts and 57 phrases. The first part measures anger state, the second part measures the anger trait, and the third part measures the ways of expressing and controlling anger. Each phrase in this questionnaire is scored on a 4-point Likert scale. In the present study, the first part, which is the anger state scale and has 15 expressions, was used. This scale measures the severity of anger and a person's willingness to express anger verbally or physically. The results indicate the desired reliability (retesting and internal consistency) and the validity of the criterion of the Persian version of the anger-status questionnaire [44].

Emotion-regulation group training sessions based on Gartz's booklet and protocol were performed on the experimental group. These sessions are mostly derived from acceptance and commitment therapies [34] and dialectical behavior therapy [44]. In addition, the examples and exercises of the group were based on the acceptance behavior therapy taken from Roemer and Orsillo. Aspects of emotion-based psychotherapy Greenberg were also included (particularly the distinction between primary and secondary emotional responses and the different methods of an effective response to each of these responses). Fourteen 90-minute sessions were held weekly, for 3.5 months, which was held in Adobe Connect and whatsapp platforms due to the Covid 19 epidemic by the first author ( $\mathrm{PhD}$. student in counseling and school counselor). Gartz, Tull, and Levy have confirmed the validity of this intervention. Table 1 summarizes the process of emotion-regulation group training sessions.

Data analysis is performed with SPSS software in two parts: descriptive and inferential statistics. In the descriptive statistics, the Mean \pm SD of the research variables were presented. In the inferential statistics section, the effectiveness of group therapy on dependent variables was investigated using a multivariate covariance statistical test.

\section{Results}

Table 2 presents the Mean \pm SD of research variables (self-injury, depression, and anger) in the experimental and control groups separately before and after the test. Multivariate analysis of covariance was used to test the hypotheses. Before testing the research hypotheses, the necessary assumptions for the analysis of covariance were examined. The underlying assumptions of analysis of covariance, including linearity, homogeneity of variance, 
Table 1. Summary of group training sessions of emotional regulation

\begin{tabular}{|c|c|c|}
\hline Sessions & Title & Contents \\
\hline 1 & $\begin{array}{l}\text { Performance of self- } \\
\text { injury behavior }\end{array}$ & $\begin{array}{l}\text { Introducing the group (introducing the leader and members, creating a sense of security and } \\
\text { respect, expressing the group structure, commitment to preventing bad behavior, the basic } \\
\text { premise of the group) } \\
\text {-Discussion about self-injury behavior, paying attention to the positive and negative conse- } \\
\text { quences of short and long term, emphasizing the contradictory results of self-injury, talking } \\
\text { about the booklet of self-injury practices, discussion of theories of self-injury behavior, explain- } \\
\text { ing the dimensions of emotion regulation that will be discussed in the group }\end{array}$ \\
\hline 2 & $\begin{array}{l}\text { Identifying negative } \\
\text { beliefs about emotions } \\
\text { and teaching emotional } \\
\text { function }\end{array}$ & $\begin{array}{l}\text { Assessing the task of the previous session, identifying the negative beliefs of group members } \\
\text { about emotions and their effects, teaching the nature and adaptive function of all emotions, } \\
\text { teaching how to identify new ways of dealing with and responding to negative opinions about } \\
\text { emotions }\end{array}$ \\
\hline 3 & Emotional awareness & $\begin{array}{l}\text { Reviewing of the previous session, talking about emotional awareness, focusing on the ways to } \\
\text { increase emotional awareness, identifying healthy and adaptive ways to express, respond, and } \\
\text { act on emotions }\end{array}$ \\
\hline 4 & Emotional awareness & $\begin{array}{l}\text { Reviewing of the previous session, completing the worksheet to increase emotional awareness } \\
\text { about several primary emotions }\end{array}$ \\
\hline 5 & $\begin{array}{l}\text { Primary and secondary } \\
\text { emotional responses }\end{array}$ & $\begin{array}{l}\text { Assessing the homework of the previous session, teaching the differences between primary } \\
\text { and secondary emotional responses - Exercises focused on identifying secondary emotional } \\
\text { responses }\end{array}$ \\
\hline 6 & $\begin{array}{l}\text { Clear and vague emo- } \\
\text { tional responses }\end{array}$ & $\begin{array}{l}\text { Assessing the homework of the previous session, teaching the differences between transparent } \\
\text { and vague emotional responses, intra-group practice }\end{array}$ \\
\hline 7 & $\begin{array}{l}\text { Avoidance / emotional } \\
\text { reluctance versus ac- } \\
\text { ceptance / emotional } \\
\text { desire }\end{array}$ & $\begin{array}{l}\text { Reviewing the previous session, expressing the experiences of group members concerning di- } \\
\text { rectly control or avoiding emotions with special emphasis on its consequences, teaching the } \\
\text { contradictory consequences to control or avoid emotions directly }\end{array}$ \\
\hline 8 & $\begin{array}{l}\text { Avoidance / emotional } \\
\text { reluctance versus ac- } \\
\text { ceptance / emotional } \\
\quad \text { desire }\end{array}$ & $\begin{array}{l}\text { Reviewing the previous session, introduction of acceptance/willingness as an alternative to } \\
\text { avoidance/reluctance, the reflection of the consequences of acceptance in comparison with } \\
\text { avoidance, and expression of their experiences in this field by group members }\end{array}$ \\
\hline 9 & $\begin{array}{l}\text { Emotion regulation } \\
\text { strategies }\end{array}$ & $\begin{array}{l}\text { Reviewing the previous session, strategies for setting and talking about effective ways to control } \\
\text { emotions, discussing the adaptive strategies for regulating emotions that have been used in the } \\
\text { past or may be helpful in the future, completing the worksheet of unhealthy ways to regulate } \\
\text { emotions }\end{array}$ \\
\hline 10 & Impulse control & $\begin{array}{l}\text { Review the previous session, discussing the booklet of impulsive behaviors, discussion about } \\
\text { the booklet of impulse control strategies }\end{array}$ \\
\hline 11 & Valuable paths & $\begin{array}{l}\text { Reviewing the previous session, training on the importance of identifying valuable paths in life, } \\
\text { education and introducing the concept of valuable paths }\end{array}$ \\
\hline 12 & Valuable paths & $\begin{array}{l}\text { Reviewing the previous session, introducing the concept of valuable action, and providing ex- } \\
\text { amples of turning valuable directions into specific and feasible actions }\end{array}$ \\
\hline 13 & $\begin{array}{l}\text { Obstacles to proper } \\
\text { behavior and commit- } \\
\text { ment }\end{array}$ & $\begin{array}{l}\text { Reviewing the previous session, talking about the booklet of obstacles to valuable actions, talk- } \\
\text { ing about commitment }\end{array}$ \\
\hline 14 & $\begin{array}{l}\text { Obstacles to valuable } \\
\text { action and commit- } \\
\text { ment }\end{array}$ & Reviewing the previous session, talking about the commitment booklet \\
\hline
\end{tabular}

normality, and homogeneity of the covariance matrix, were examined, which are mentioned in the following.

One of the assumptions of analysis of covariance is the linearity of the relationship between the dependent variable and the auxiliary variable. In this Pre-test study, self-injury, depression, and anger were considered auxiliary variables. The Pearson correlation coefficients were 0.94 between self-injury Pre-test with post-test $(\mathrm{P}=0.0001), 0.65$ between depression Pre-test with post- test $(\mathrm{P}=0.0001)$, and 0.55 between anger Pre-test with post-test $(\mathrm{P}=0.001)$. These findings show that the assumption of linearity has been observed. Also, the results of Levene's test show that the assumption of the equality of variance has been established.

The results of Table 3 show that the KolmogorovSmirnov test is significant in the self-injury and the anger post-test for the experimental group, so the distribution of data in these variables is not normal. The Kolmogorov- 
Table 2. Mean $\pm S D$ scores of research variables in the experimental and control groups

\begin{tabular}{cccc}
\hline & & \multicolumn{2}{c}{ Mean \pm SD } \\
Variables & Stage & Experimental Group & Control Group \\
\cline { 3 - 4 } & Pre-test & $5.53 \pm 4.51$ & $5.00 \pm 3.94$ \\
Self-injury & Post-test & $5.87 \pm 5.02$ & $7.73 \pm 5.80$ \\
\cline { 3 - 4 } Depression & Pre-test & $21.33 \pm 7.21$ & $22.27 \pm 5.57$ \\
& Post-test & $15.00 \pm 5.34$ & $24.20 \pm 4.75$ \\
Anger & Pre-test & $50.40 \pm 9.70$ & $46.20 \pm 7.38$ \\
& Post-test & $37.53 \pm 6.93$ & $47.27 \pm 6.25$
\end{tabular}

IPA:

Smirnov test is not significant for the other variables in the experimental and control groups, so the distribution of data in them is normal. Also, the value of the $\mathrm{M}$ box is calculated to be 5.261, which is significant at the level of 0.59 . Since this value is greater than the significance level of 0.05 , the null hypothesis that the covariance matrix is homogeneous is confirmed. Thus, the assumption of covariance matrix homogeneity is established as one of the assumptions of multivariate analysis of covariance in the current study.

In Table 4, there is a significant difference between the two groups regarding self-injury, depression, and anger $(\mathrm{P}<0.0001)$. The comparison of the two groups in each of the variables can be seen below.

As the $\mathrm{F}$ values in Table 5 show, there is a significant difference between the experimental and control groups regarding self-injury, depression, and anger $(\mathrm{P}<0.0001)$.

\section{Discussion}

The present study results showed that emotional-regulation group training affected the self-injury behavior of adolescent girls, and this intervention reduced selfinjury. This result is consistent with the previous studies on the effectiveness of group therapy of emotional regulation [35-37, 45] and dialectical behavior therapy by individual and group methods [46-48], and acceptance and commitment therapy with compassion [49]. It can be said that emotional regulation is a commonly reported practice of self-injury [21]. The skills taught to the subjects during the program (especially emotion regulation and mindfulness skills) can reduce self-injury behavior in individuals. Therefore, at the end of the sessions, by acquiring emotional regulation skills, including emotion recognition, emotion perception, reducing emotional vulnerability, and reducing emotional suffering, individuals will become more successful in regulating and controlling emotions than before, and consequently, their dysfunctional behaviors are reduced.

Table 3. The Kolmogorov-Smirnov test for normalization of dependent variables scores

\begin{tabular}{|c|c|c|c|c|}
\hline Variables & Groups & Statistics & df & Sig. \\
\hline \multirow{2}{*}{ Self-injury post-te } & Experimental & 0.249 & 15 & 0.013 \\
\hline & Control & 0.217 & 15 & 0.056 \\
\hline \multirow{2}{*}{ Depression post- } & Experimental & 0.173 & 15 & 0.200 \\
\hline & Control & 0.155 & 15 & 0.200 \\
\hline \multirow{2}{*}{ Anger post-te } & Experimental & 0.250 & 15 & 0.012 \\
\hline & Control & 0.209 & 15 & 0.076 \\
\hline
\end{tabular}


Table 4. Results of multivariate analysis of covariance in the experimental and control groups

\begin{tabular}{cccc}
\hline Index & F & df & Sig. \\
\hline Pillai's Trace & 67.51 & 3 & 0.0001 \\
\hline Wilks' Lambda & 67.51 & 3 & 0.0001 \\
\hline Hotelling's Trace & 67.51 & 3 & 0.0001 \\
\hline Roy's Largest Root & 67.51 & 3 & 0.0001 \\
\hline
\end{tabular}

URE

The present study results showed that group training in emotional regulation reduces depression in adolescent girls. This result is consistent with previous studies [28, 38, 45, 47, 48]. Emotional disorder predicts future psychological damage and can be a key factor in developing depression. Research has shown that high levels of positive emotions and reduction of negative emotions play an important role in positive judgment and self-perception [39]. Emotional regulation skills enable individuals to reduce processes, such as self-blame, blaming others, and mental rumination; this kind of control increases their acceptance [28]. Emotional-regulation training by informing people about positive emotions, their acceptance, and timely expression plays an essential role in reducing physical and mental symptoms, improving social functioning and levels of mental health. Thus, emotion regulation involves numerous regulatory processes and strategies, including cognitive, physical, social, and behavioral dimensions. Emotion regulation strategies are used to increase adjustment and adaptation to manage emotions and are part of adaptation strategies related to the experience and treatment of emotional and physical disorders. Therefore, emotional regulation reduces negative emotions, such as depression, and increases positive emotions and adaptive behavior [39].

The current study results indicated that group training in emotion regulation affects the level of anger in adolescent girls, and this intervention reduces anger. This result is consistent with previous research $[28,38,48$, 50]. To explain this finding, it can be said that one of the important causes in the development and occurrence of aggressive behaviors is the existence of a disorder in emotional regulation. According to experts, emotional regulation disorder predicts future psychological damage and the emergence of interpersonal sensitivities and aggressive behavior. One of the appropriate strategies in this field is to acquire emotion regulation skills [38]. Human beings always seek to know and evaluate the environment, and knowledge and evaluation play an important role in shaping their behaviors. Aggressive behavior is the result of misjudgment of the situation. One of the causes of anger and aggression has been the incorrect assessment of the situation, which uses anger training techniques to regulate anger [39]. Emotion-regulation training emphasizes exercises and skills which their application leads to the acceptance of emotional problems, acceptance of a healthy lifestyle, doing the opposite action against negative emotions, which ultimately leads to the facilitation of change [38].

\section{Conclusion}

According to the study results, emotional-regulation group training reduces the rate of self-injury and the emotions of depression and anger in adolescents. Adolescence is accompanied by profound biological, psychological, and social changes that upset the physical and mental balance. As life gets more complicated, the amount of positive and negative emotions increases and leads to different reactions of people to problems. In recent years, self-injury behavior and the rate of de-

Table 5. Results of multivariate analysis of covariance between the two groups according to the research variables

\begin{tabular}{cccccc}
\hline Variables & Sums of Squares & df & Mean Squares & F & 0.0001 \\
\hline Post-test self-injury & 43.48 & 1 & 43.48 & 23.83 & 96.30 \\
Post-test depression & 559.58 & 1 & 559.58 & 139.36 & 0.0001 \\
Post-test anger & 1058.12 & 1 & 1058.12 & 0.001 \\
\hline
\end{tabular}


pression and anger have become more prevalent among adolescents. Adolescents constitute a significant part of the population and are the main assets that play an important role in governing the country's future. It is necessary to study and eliminate the underlying factors that cause mental and psychological problems and maintain the health of these future makers. This research provides helpful solutions for therapists, psychologists, counselors, educators, and all people who interact with adolescents in different educational, social, cultural environments. One of the limitations of the current research is the limited number of studies conducted concerning treatment or group training of emotional regulation and the limited study population. It is suggested that future researchers work on the effectiveness of this type of intervention on other kinds of emotions, emotional regulation, and diverse statistical communities.

\section{Ethical Considerations}

\section{Compliance with ethical guidelines}

This research project was approved by the Ethics Committee of Hormozgan University of Medical Sciences (Code: IR.HUMS.REC.1399.348). Research objectives, procedures, benefits, voluntary nature of the company, and confidentiality were explained to the participants. The researchers reaffirms participants' understanding of their right to withdraw from the study for any reason. In addition, signed informed consent forms were obtained from the participants.

\section{Funding}

This research did not receive any grant from funding agencies in the public, commercial, or non-profit sectors.

\section{Authors' contributions}

Conceptualization and supervision: Abdolvahab Samavi and Tayebeh Vafaei; Methodology: Julia Whisenhunt; Investigation, writing-original draft, and writing-review \& editing: All authors; Data collection: Tayebeh Vafaei; Data analysis: Samaneh Najarpourian.

\section{Conflict of interest}

The authors declared no conflict of interest.

\section{Acknowledgments}

Researchers would like to thank the cooperation of Fars Province Education for conducting research on students.

\section{References}

[1] Zetterqvist M. The DSM-5 diagnosis of nonsuicidal self-injury disorder: A review of the empirical literature. Child Adolescent Psychiatry and Mental Health. 2015; 9:31. [DOI:10.1186/s13034 015-0062-7] [PMID] [PMCID]

[2] Han S. Influencing Factors of Adolescent Self-Injury Behavior. Advances in Psychology. 2019; 9(2):248-54. [DOI:10.12677/ ap.2019.92032]

[3] Watson D, Tellegen A. Toward a consensual structure of mood. Psychological Bulletin. 1985; 98(2):219-35. [DOI:10.1037//00332909.98.2.219] [PMID

[4] Ramazani S, Aramjoo H, Ramazani A, Hajipoor R, Naseri M. [Survey of stress, anxiety and depression in paramedical students of birjand university of medical sciences, 2016 (Persian)] Horizons of Medical Education Development. 2020; 11(1):5-14. [DOI:10.22038/hmed.2020.47030.1018]

[5] Novaco RW, Chemtob CM. Anger and combat-related posttraumatic stress disorder. Journal of Traumatic Stress. 2002 15(2):123-32. [DOI:10.1023/A:1014855924072] [PMID]

[6] Foulkes L, Blakemore SJ. Studying individual differences in human adolescent brain development. Nature Neurosciences. 2018; 21(3):315-23. [DOI:10.1038/s41593-018-0078-4] [PMID]

[7] Dryfoos JG. Adolescents at risk: Prevalence and prevention. Oxford: Oxford University Press; 1991. https:// books.google.com/ books?hl=en\&lr=\&id=aWQ0zhg52B8C\&oi=fnd\&pg=

[8] Prinstein MJ, Heilbron N, Guerry JD, Franklin JC, Rancourt D, Simon $\mathrm{V}$, et al. Peer influence and nonsuicidal self injury: Longitudinal results in community and clinically-referred adolescent samples. Journal of Abnormal Child Psychology. 2010; 38(5):66982. [DOI:10.1007/s10802-010-9423-0][PMID][PMCID]

[9] Nock M. The Oxford Handbook of Suicide and Self-Injury. Oxford: Oxford University Press; 2014. [DOI:10.1093/oxford$\mathrm{hb} / 9780195388565.001 .0001]$

[10] Madge N, Hawton K, McMahon EM, Corcoran P, De Leo D, de Wilde EJ, et al. Psychological characteristics, stressful life events and deliberate self-harm: Findings from the child \& adolescent self-harm in Europe (CASE) study. European Child \& Adolescent Psychiatry. 2011; 20(10):499-508. [DOI:10.1007/s00787-0110210-4] [PMID]

[11] Bresin K, Schoenleber M. Gender differences in the prevalence of nonsuicidal self-injury: A meta-analysis. Clinical Psychology Review. 2015; 38:55-64. [DOI:10.1016/j.cpr.2015.02.009] [PMID]

[12] Bavazin F, Sepahvandi MA, Ghazanfari F. [The effectiveness of communication skills training on social responsibility of depressed adolescent girls (Persian)]. Journal of Nursing Education. 2018; 7(1):48-54. http:/ /jne.ir/article-1-861-en.html

[13] Piccinelli M, Wilkinson G. Gender differences in depression. Critical review. British Journal of Psychiatry. 2000; 177:486-92 [DOI: 10.1192/bjp.177.6.486] [PMID]

[14] Pullen L, Modrcin MA, McGuire SL, Lane K, Kearnely M, Engle $S$. Anger in adolescent communities: How angry are they? Pediatric Nursing. 2015; 41(3):135-40. [PMID]

[15] Bor W. Prevention and treatment of childhood and adolescent aggression and antisocial behaviour: A selective review. Australian and New Zealand Journal of Psychiatry. 2004; 38(5):373-80. [DOI:10.1080/j.1440-1614.2004.01366.x] [PMID] 
[16] Garnefski N, Kraaij V. Relationships between cognitive emotion regulation strategies and depressive symptoms: A comparative study of five specific samples. Personality and Individual differences. 2006; 40(8):1659-69. https://www.sciencedirect. com/science/article/abs/pii/S0191886906000377

[17] Berking M, Orth U, Wupperman P, Meier LL, Caspar F. Prospective effects of emotion-regulation skills on emotional adjustment. Journal of Counseling Psychology. 2008; 55(4):485-94. [DOI:10.1037/a0013589] [PMID]

[18] Gratz KL, Roemer L. Multidimensional assessment of emotion regulation and dysregulation: Development, factor structure, and initial validation of the difficulties in emotion regulation scale. Journal of Psychopathology and Behavioral Assessment. 2004; 26:41-54. [DOI:10.1023/B:JOBA.0000007455.08539.94]

[19] Timoney LR, Holder MD. Emotional processing deficits and happiness. Berlin/Heidelberg, Germany: Springer Science \& Business Media; 2013. https://link.springer.com/ book/10.1007/978-94-007-7177-2

[20] Chapman AL, Gratz KL, Brown MZ. Solving the puzzle of deliberate self-harm: The experiential avoidance model. Behavior Research and Therapy. 2006; 44(3):371-94. [DOI:10.1016/j. brat.2005.03.005][PMID]

[21] Andover MS, Morris BW. Expanding and clarifying the role of emotion regulation in nonsuicidal self-injury. The Canadian Journal of Psychiatry. 2014; 59(11):569-75. [DOI:10.1177/070674 371405901102] [PMID] [PMCID]

[22] Lloyd-Richardson EE, Perrine N, Dierker L, Kelley ML. Characteristics and functions of non-suicidal self-injury in a community sample of adolescents. Psychological Medicine. 2007; 37(8):1183-92. [DOI:10.1017/S003329170700027X] [PMID] [PMCID]

[23] Peterson J, Freedenthal S, Sheldon C, Andersen R. Nonsuicidal self injury in adolescents. Psychiatry. 2008; 5(11):20-6. [PMID] [PMCID]

[24] Chapman AL, Dixon-Gordon KL. Emotional antecedents and consequences of deliberate self-harm and suicide attempts. Suicide and Life Threatening Behavior. 2007; 37(5):543-52. [DOI:10.1521/suli.2007.37.5.543] [PMID]

[25] Madge N, Hewitt A, Hawton K, de Wilde EJ, Corcoran P Fekete S, et al. Deliberate self-harm within an international community sample of young people: Comparative findings from the child \& adolescent self-harm in Europe (CASE) study. Journal of Child Psychology and Psychiatry. 2008; 49(6):667-77. [DOI:10.1111/j.1469-7610.2008.01879.x] [PMID]

[26] Greene D, Boyes M, Hasking P. The associations between alexithymia and both non-suicidal self-injury and risky drinking: A systematic review and meta-analysis. Journal of Affective Disorders. 2020; 260:140-66. [DOI:10.1016/j.jad.2019.08.088] [PMID]

[27] Dillon DG, Ritchey M, Johnson BD, LaBar KS. Dissociable effects of conscious emotion regulation strategies on explicit and implicit memory. Emotion. 2007; 7(2):354-65.[DOI:10.1037/15283542.7.2.354] [PMID]

[28] Sheybani H, Mikaeili N, Narimani M. [The effectiveness of cognitive-behavioral therapy and emotion regulation training on irritability, depression, anxiety, and emotion regulation in adolescents with disruptive mood dysregulation disorder (Persian)]. Journal of Clinical Psychology. 2020; 12(2): 41-50. [DOI:10.22075/jcp.2020.19250.1778]
[29] Gratz KL, Tull MT. Extending research on the utility of an adjunctive emotion regulation group therapy for deliberate self-harm among women with borderline personality pathology. Journal of Personality Disorders. 2011; 2(4):316-26. [DOI:10.1037/a0022144] [PMID]

[30] Stallard P, Porter J, Grist R. A smartphone App (blueice) for young people who self-harm: Open phase 1 pre-post trial. JMIR Mhealth Uhealth. 2018; 6(1):e32. [DOI:10.2196/ mhealth.8917] [PMID] [PMCID]

[31] Van den Brink W, Haasen C. Evidenced-based treatment of opioid-dependent patients. The Canadian Journal of Psychiatry. 2006; 51(10):635-46. [DOI:10.1177/0706743706051010 03] [PMID]

[32] Hokm Abadi ME, Rezaei AM, Asghari Ebrahim Abad MJ, Salamat A. [The effect of group new reality therapy based on choice theory on hopefulness in drug abusers (Persian)] Studies in Medical Sciences. 2014; 25(8):752-9. http://umj. umsu.ac.ir/article-1-2450-fa.html

[33] Salimi Bajestani H . [Group counseling strategies in school (Persian)]. Journal of School Counseling. 2009; 4(3):48-9. http://ensani.ir/file/download/article/20101108130739

[34] Gratz KL, Gunderson JG. Preliminary data on an acceptance-based emotion regulation group intervention for deliberate self-harm among women with borderline personality disorder. Behavior Therapy. 2006; 37(1):25-35. [DOI: 10.1016/j.beth.2005.03.002] [PMID]

[35] Sahlin H, Bjureberg J, Gratz KL, Tull MT, Hedman E, Bjärehed J, et al. Emotion regulation group therapy for deliberate self-harm: A multi-site evaluation in routine care using an uncontrolled open trial design. BMJ Open. 2017; 7(10):e016220. [DOI:10.1136/bmjopen-2017-016220] [PMID] [PMCID]

[36] Gratz KL, Bardeen JR, Levy R, Dixon-Gordon KL, Tull MT. Mechanisms of change in an emotion regulation group therapy for deliberate self-harm among women with borderline personality disorder. Behavior Research and Therapy. 2015; 65:29-35. [DOI:10.1016/j.brat.2014.12.005] [PMID] [PMCID]

[37] Ataie Sh, Gharraee B, Asgharnejad AA, Mohammadi Shahboulaghi $F$. [The effectiveness of emotion regulation therapy for adolescents with non-suicidal self-injury disorder: A case report (Persian)]. Journal of Biochemical Technology. 2018; Special Issue9(2):60-4. https://jbiochemtech.com/article/ the-effectiveness-of-emotion-regulation-therapy-for-adoles

[38] Motevalizadeh T, ebrahimbabaie F, ghazanfari F. [The effect of gross process model-based emotion regulation training on aggression and depression in first grade high school students in Tehran (Persian)]. Zanko Journal of Medical Sciences Kurdistan University of Medical Sciences. 2020; 21(69):24-34. http:/ / zanko.muk.ac.ir/article-1-502-en.html

[39] Kazemi A, Peyman A, Kazemie Rezaei S, Salehi A. [Emotion regulation training based on dialectical behavior therapy effectiveness on reducing students' anxiety and anger (Persian)]. Armaghane Danesh. 2020; 25 (4):451-65. http:/ / armaghanj.yums.ac.ir/article-1-2592-en.html

[40] Dehghani Y, Golestaneh S, Zangouei S. [The effectiveness of emotion regulation training on academic burnout, social acceptance and affective control of students with learning disabilities (Persian)]. Journal of Applied Psychology. 2018; 12(2):163-82. https:/ /apsy.sbu.ac.ir/article_97046. html?lang=en 
[41] Dehghani Y, Hekmatian S, Kamran L. [Effectiveness of emotional regulation training in improving adaptability and social adequacy of students with learning disabilities (Persian)]. Journal of Applied Psychology. 2019; 13(2):229-50. [DOI:10.29252/apsy.13.2.229]

[42] Payvastegar M. [The rate of deliberate self- harming in girls students and relationship with loneliness \& Attachment styles (Persian)]. Journal of Psychological Studies. 2013; 9(3):29-52. [DOI:10.22051/psy.2013.1750]

[43] Habibi M, Hamediniya E, Asgarinejad F, Kholghi H. [Psychometric properties of kutcher adole csent's depression scale. Applied Research in Educational Psychology (Persian)]. 2016; 2(2):15-28. http://aep.journals.pnu.ac.ir/article_2279. html?lang=en

[44] Asghari Moghadam MA, Moghadasi M, Dibajnia P. [The reliability and criterion validity of a Persian version of the statetrait anger expression inventory-2 (staxi-2) in a clinical sample (Persian)]. Clinical Psychology and Personality. 2011; 9(2):75-94. http://cpap.shahed.ac.ir/article_2656.html?lang=en

[45] Gratz KL, Tull MT, Levy R. Randomized controlled trial and uncontrolled 9-month follow-up of an adjunctive emotion regulation group therapy for deliberate self-harm among women with borderline personality disorder. Psychological Medicine. 2014; 44(10):2099-112. [DOI:10.1017/ S0033291713002134] [PMID]

[46] Saffarinia M, Nikoogoftar M, Damavandian A. [The effectiveness of dialectical behavior therapy (dbt) on reducing self-harming behaviors in juvenile offenders in Tehran's juvenile correction and rehabilitation centre (Persian)]. Clinical Psychology Studies. 2014; 4(15):141-58. https:/ /jcps.atu.ac.ir/ article_349.html?lang=en

[47] Fleischhaker C, Böhme R, Sixt B, Brück C, Schneider C, Schulz E. Dialectical behavioral therapy for adolescents (DBTA): A clinical trial for patients with suicidal and self-injurious behavior and borderline symptoms with a one-year follow-up. Child and Adolescent Psychiatry Mental Health. 2011; 5(1):3. [DOI:10.1186/1753-2000-5-3] [PMID] [PMCID]

[48] Salemi Khameneh A, Ghorbani S, Motahedi A. [The effectiveness of dialectical behavior therapy on emotion regulation, positive and negative affect, aggressive and self-injury behavior of 13-16 year old female students (Persian)]. Journal of Medical Council of Iran. 2018; 36(4):213-20. http://jmciri. ir/article-1-2865-en.html

[49] Peymannia B, hamid N, Mhmudalilu M. [The effectiveness of act matrix with compassion on self-injury behaviors and quality of life of students with symptoms of borderline personality disorders (Persian)]. Journal of Psychological Achievements. 2018; 25(1):23-44. [DOI:10.22055/psy.2018.23581.1905]

[50] Peymannia B, Hamid N, Mehrabizadehhonarmand M, Mahmoudalilu M. [The effectiveness of dialectic behavioral therapy-family and child skills training (dbt-fst) on impulsivity and quality of life in girls with self-harm behaviors (Persian)]. Iranian Journal of Rehabilitation Research in Nursing. 2018; 4(3):8-17. http://ijrn.ir/article-1-328-en.html 